\title{
A methyl-deficient diet fed to rats during the pre- and peri- conception periods of development modifies the hepatic proteome in the adult offspring
}

\author{
Christopher A. Maloney - Susan M. Hay • \\ Martin D. Reid · Gary Duncan · Fergus Nicol · \\ Kevin D. Sinclair · William D. Rees
}

Received: 6 October 2011/Accepted: 2 August 2012/Published online: 21 August 2012

(C) Springer-Verlag 2012

\begin{abstract}
A methyl-deficient diet (MD) lacking folic acid and the associated methyl donors choline and methionine, fed to the laboratory rat during the periods of oocyte and embryo development, has been shown to programme glucose metabolism in the offspring. The hepatic proteome of the male offspring of female rats fed MD diets for 3 weeks prior to mating and for the first 5 days of gestation has been examined by 2 -dimensional gel electrophoresis. Three groups of differentially abundant proteins associated with energy metabolism, amino acid metabolism and antioxidant defence were identified in the soluble proteins extracted from the liver from the MD offspring at both 6 and 12 months of age. Altered mitochondrial activity in other programming models leads to a similar pattern of differential protein abundance. Two of the differentially abundant proteins were identified as GAPDH and PGK-1 by mass spectrometry. Western blotting showed that there
\end{abstract}

Present Address:

C. A. Maloney

School of Medical Sciences, Faculty of Medicine,

The University of New South Wales, Sydney,

NSW 2052, Australia

S. M. Hay · M. D. Reid · G. Duncan · F. Nicol ·

W. D. Rees $(\bowtie)$

The Rowett Institute of Nutrition and Health,

The University of Aberdeen, Greenburn Road, Bucksburn,

Aberdeen AB21 9SB, Scotland, UK

e-mail:w.rees@abdn.ac.uk

K. D. Sinclair

School of Biosciences, University of Nottingham,

Sutton Bonington Campus, Loughborough,

Leicestershire LE12 5RD, UK were multiple isoforms of both proteins with similar molecular weights but different isoelectric points. The differentially abundant spots reduced in the MD offspring corresponded to minor isoforms of GAPDH and PGK-1. The levels of PPAR-alpha, SREBP and glucocorticoid receptor mRNAs associated with other models of prenatal programming were unchanged in the MD offspring. The data suggest that a diet deficient in folic acid and associated methyl donors fed during the peri-conception and early preimplantation periods of mammalian development affects mitochondrial function in the offspring and that the posttranslational modification of proteins may be important.

Keywords Foetal programming - Methylation - PEPCK · Mitochondria

\begin{tabular}{|c|c|}
\hline \multicolumn{2}{|l|}{ Abbreviations } \\
\hline ACC-1 & Acetyl-CoA carboxylase \\
\hline HOMA & Homoeostasis model \\
\hline L-CPT-1 & Carnitine palmitoyl transferase \\
\hline GAPDH & $\begin{array}{l}\text { Glyceraldehyde-3-phosphate } \\
\text { dehydrogenase }\end{array}$ \\
\hline MD & Methyl deficient \\
\hline PEPCK & $\begin{array}{l}\text { Phosphoenolpyruvate } \\
\text { carboxykinase }\end{array}$ \\
\hline PGC- $1 \alpha$ & PPAR- $\gamma$ co-activator- $1 \alpha$ \\
\hline PGK1 & Phosphoglycerate kinase \\
\hline PPAR $-\alpha$ and PPAR- $-\gamma$ & $\begin{array}{l}\text { Peroxisome proliferator-activated } \\
\text { receptors alpha and gamma }\end{array}$ \\
\hline SREBP-1c & $\begin{array}{l}\text { Sterol response element binding } \\
\text { protein }\end{array}$ \\
\hline Udpgdh & UDP-glucose dehydrogenase \\
\hline GccR & Glucocorticoid receptor \\
\hline oGTT & Oral glucose tolerance test \\
\hline
\end{tabular}




\section{Introduction}

There is a growing body of evidence to show that an imbalance in the maternal diet during the peri-conception and early preimplantation periods of mammalian development permanently programmes the metabolism of the offspring. The substrates and cofactors involved in methyl metabolism are believed to be especially important during these very early stages of development (Fernandez-Gonzalez et al. 2004; Sinclair et al. 2007b; Hochberg et al. 2010). Studies of animals from several diverse species have shown that methyl-deficient (MD) diets, that is, deficient in folic acid, choline, methionine and vitamins in the B group (folic acid and $\mathrm{B}_{12}$ ), fed around the time of conception programme the insulin axis and hence glucose metabolism in the offspring. Sheep embryos derived from ewes fed MD diets develop into adults that are heavier, fatter and are insulin-resistant (Sinclair et al. 2007a). A similar change in the insulin axis has also been observed in the male offspring of the laboratory rat exposed to MD diets during oocyte maturation and early development (Maloney et al. 2011). In this model, the Homoeostasis Model Assessment (HOMA) index and peak insulin during an oral glucose tolerance test (oGTT) were increased at 6 months of age, and this change in glucose homoeostasis persisted so that by 12 months of age the peak glucose concentration during oGTT was higher, despite higher peak insulin concentrations. Other treatments that perturb the preimplantation embryo such as assisted reproductive technologies (Scott et al. 2010) and somatic cell nuclear transfer (Tamashiro et al. 2003) have also been reported to change insulin action, producing a similar phenotype to the MD offspring. However, the mechanism underlying the peri-conception programming of glucose metabolism and insulin action is unknown.

The liver has been shown to be an important target organ for metabolic programming in many of the animal models used to demonstrate the developmental origins of health and disease. For example, the expression of key hepatic enzymes such as phosphoenolpyruvate carboxykinase (PEPCK), acyl-CoA carboxylase-1 (ACC-1) and liver carnitine palmitoyl transferase-1 (L-CPT-1) is modified in the offspring of rats fed a low-protein diet during pregnancy (Desai et al. 1997; Zhang and Byrne 2000; Maloney et al. 2003; Rees et al. 2006; Maloney et al. 2007). This programming of the liver extends to the preimplantation period, with a twofold increase in hepatic PEPCK expression in male foetuses of mice fed a low-protein diet during the first 5 days following conception (Kwong et al. 2007). Because the liver has such a central role in metabolic homoeostasis, it is a promising target tissue for programming by early MD diet exposure.
Early preimplantation development is characterised by precise, persistent changes in epigenetic marks that completely reprogramme the mammalian genome by methylation of cytosine residues close to a number of important genes (Santos and Dean 2004). A growing number of studies have associated changes in the methylation of regulatory DNA sequences with developmental programming of offspring metabolism. These sequences include those for integrated viral sequences (Waterland and Jirtle 2003), PPAR-alpha, glucocorticoid receptor (Lillycrop et al. 2005), angiotensin receptor (Bogdarina et al. 2007, 2010), liver $X$ receptor (van Straten et al. 2010) and hepatocyte nuclear factor Hnf4a (Sandovici et al. 2011). Critically, evidence from studies in both sheep and rodents shows that inappropriate methyl nutrition specifically imposed during peri-conception and early preimplantation development persistently modifies the patterns of DNA methylation in adult tissues (Waterland and Michels 2007; Sinclair et al. 2007b). Methylation reactions are also important for the posttranslational modification of proteins; for example, an MD diet fed during dam gestation and lactation has been shown to alter fatty acid oxidation and energy metabolism in the myocardium of rat offspring through imbalanced methylation/acetylation of PGC-1 alpha (Garcia et al. 2011).

In this study, we have compared the proteomic profiles of soluble proteins from the male offspring of rats fed MD diets during the pre- and postconception period with those of control animals. This gives a broad picture of the changes in proteins associated with a wide range of cell function. We have also measured the expression of some of the candidate genes associated with altered epigenetic regulation in other models of prenatal programming to test the possibility that epigenetic marks acquired during the peri-conception and immediate preimplantation stages of development modify hepatic gene expression.

\section{Methods}

Animals

All experimental procedures were approved by the Ethical Review Committee of the Rowett Research Institute and conducted in accordance with the UK Animals (Scientific Procedures) Act, 1986. The experiment to produce the offspring and their physiological phenotype has been described previously (Maloney et al. 2011). Briefly, female rats were allocated into two groups fed either a complete semi-synthetic diet (CON) or a methyl-deficient diet (MD) with no folic acid, $0.05 \%$ choline and approximately half the recommended content of methionine for 3 weeks prior to mating and for the first 5 days of gestation. From day 5 , 
both groups received a complete semi-purified diet until birth, and thereafter, dams and offspring were fed nonpurified diet for the remainder of the experiment (CRM (P) breeder and grower diet 801722, Special Diet Services, Witham Essex UK). Offspring were killed at 6 and 12 months of age, $3 \mathrm{~h}$ after being subjected to an oral glucose tolerance test (see Maloney et al. 2011 for details), and samples of the liver were removed, rapidly frozen and stored at $-80^{\circ} \mathrm{C}$.

\section{Proteomics}

Analysis of the soluble proteome was carried out as described previously (McNeil et al. 2008). Liver samples were chosen randomly from eight male offspring (one per litter) of either the CON or MD groups. Pieces of frozen liver $( \pm 125 \mathrm{mg})$ were homogenised in $500 \mu \mathrm{l}$ extraction buffer ( $\mathrm{pH} 7.1$ ) containing $50 \mathrm{mM}$ Tris, $100 \mathrm{mM} \mathrm{KCl}$, $20 \%$ glycerol, $1.4 \mu \mathrm{M}$ pepstatin A, $1.0 \mathrm{mM}$ PMSF and Complete $^{\mathrm{TM}}$ protease inhibitor cocktail (Boehringer Mannheim). The homogenate was centrifuged for $30 \mathrm{~min}$ at $100,000 \times g$ at $4{ }^{\circ} \mathrm{C}$ (Beckman TL-100 centrifuge). Proteins in the supernatant $(300 \mu \mathrm{g}$ from each extract) were separated in the first dimension on immobilised $\mathrm{pH}$ gradient strips (pI 3-10; BioRad, Hemel Hempstead, UK) and in the second dimension on an $18 \times 18$-cm SDS polyacrylamide gel at $200 \mathrm{~V}$ for $9.5 \mathrm{~h}$. Molecular weights were determined with a Bio-Rad Precision Plus Protein $\mathrm{Mr}$ standard. Gels were stained with colloidal coomassie brilliant blue, washed, scanned and analysed using PDQuest v7 software (BioRad.). Spots corresponding to differentially abundant proteins were excised from the gels using a robotic spot cutter (BioRad), and following trypsin digestion, protein identities were determined by mass spectrometry using either MALDI-TOF (Voyager-DE PRO, Applied Biosystems, Warrington, Cheshire, UK) or LC/ MS/MS (Q-trap Applied Biosystems). The mass spectra were corrected for isotope abundance, and the resulting peptide mass list profiles were analysed using the Matrix Science 'Mascot' web tool (http://www.matrixscience.com ). The Mascot database search criteria allowed 1 missed cleavage, carbamidomethyl modification of cysteine; partial oxidation of methionine, a charged state of $\mathrm{MH}+$ and positive identities of at least $20 \%$ matched peptides covering at least $10 \%$ of the protein sequence. Positive matches with proteins in the database were assigned at a probability value of $P<0.05$.

\section{Western blotting}

Protein samples (200 $\mu \mathrm{g}$ of each extract) were separated by two-dimensional gel electrophoresis (pI 3-10 in the first dimension and in the second dimension on Criterion AnyKd gels (Biorad)) and blotted using the Criterion wet blot system (Biorad). Antibodies were obtained from R\&D Systems (Abingdon, Oxfordshire, UK), and conditions for Western blotting were as recommended by the manufacturer. The primary antibodies PGK1 (Cat No AF5455) and GAPDH (Cat No AF5718) were used at a concentration of $0.8 \mu \mathrm{g} / \mathrm{ml}$ and $0.25 \mu \mathrm{g} / \mathrm{ml}$, respectively, and secondary antibody (Cat No HAF109) was used at $0.1 \mu \mathrm{g} / \mathrm{ml}$. The blots were visualised by ECL (Imobilon Western Chemiluminescent HRP substrate Cat No WBKLSO500, Millipore, Watford UK) and imaged with a Fuji Imager LAS3000.

\section{Real-time PCR}

Total RNA was extracted from samples of liver using the Trizol reagent (Sigma, Poole, Dorset, UK) as described previously (Maloney et al. 2005). Samples of $50 \mathrm{ng}$ total RNA were reverse transcribed using the TaqMan Reverse Transcription Reagents Kit (Applied Biosystems, Warrington, Cheshire, UK) primed with random hexamers. The levels of PPAR-alpha, PPAR-gamma, SREBP-1c, ACC-1, L-CPT- 1 and GccR cDNA were measured using the SYBR Green real-time PCR kit (Applied Biosystems) using the primer sequences described previously (Watts et al. 2005; McNeil et al. 2008). The levels of the remaining cDNAs were measured using the TaqMan gene expression assay (PEPCK Assay ID Rn01529009_g1; GAPDH (G3PDH) Assay ID Rn99999916_s1; UGDH Assay ID Rn00580047_m1 from Applied Biosystems). Relative target quantity was calculated from the standard curve, and the results expressed as the ratio of the product relative to the 18S rRNA.

\section{PEPCK assay}

PEPCK activity was estimated by the method of (Petrescu et al. 1979) modified for a 96-well plate format. Briefly, samples of liver were homogenised in 10 volumes of icecold buffer (0.25 M Sucrose, $5 \mathrm{mM}$ Hepes (pH 7.4)) and centrifuged at $100,000 \times \mathrm{g}$ for $30 \mathrm{~min}$. The assay was conducted in a final volume of $0.25 \mathrm{ml}$ containing; $25 \mathrm{mM}$ Tris- $\mathrm{HCl}$ (pH 7.4), $20 \mathrm{mM} \mathrm{NaHCO}_{3}, 1 \mathrm{mM} \mathrm{MgCl}_{2}$, $0.1 \mathrm{mM}$ NADH, $0.5 \mathrm{mM}$ Phosphoenol pyruvate, $2 \mathrm{U}$ malate dehydrogenase and $0.025 \mathrm{ml}$ of the homogenate. The reaction was initiated by the addition of $0.15 \mathrm{mM}$ dGTP and monitored by the change in absorption at $340 \mathrm{~nm}$. The background rate was determined in a duplicate set of wells where $\mathrm{NaHCO}_{3}$ was omitted from the reaction mixture.

\section{GAPDH assay}

Glyceraldehyde-3-phosphate-dehydrogenase activity was assayed by the method described in the Worthington 
Biochemical Corporation Enzymes manual (www.worthingtonbiochem.com/GAPD/assay.html) modified for a 96-well plate format. Briefly, the assay was conducted in a final volume of $0.25 \mathrm{ml}$ containing $9 \mathrm{mM}$ sodium pyrophosphate ( $\mathrm{pH} 8.5$ ), $18 \mathrm{mM}$ sodium arsenate, $0.25 \mathrm{mM}$ NAD, $3.3 \mathrm{mM}$ DTT and $0.025 \mathrm{ml}$ of the enzyme extract used for the PEPCK assay. The reaction was started by the addition of $0.5 \mathrm{mM}$ Glyceraldehyde-3-phosphate and monitored by the change in absorption at $340 \mathrm{~nm}$.

\section{Statistical analysis}

Data are presented as mean \pm SEM. Scans of the proteomic gels were normalised using the PDQuest software to determine the mean corrected spot density. The spot density for each discrete protein on the control gels was compared with the density of the corresponding spot on the MD gels using Student's $t$ test. The gene expression data and enzyme activities were analysed by one-way ANOVA followed by Fisher's multiple comparison test (Genstat 7 statistical package, Lawes Agricultural Trust, Rothamsted Experimental Station, Harpenden, Herts, UK).

\section{Results}

\section{Proteomics}

Soluble proteins prepared from the livers of the male offspring killed at 6 months of age and where possible their male siblings killed at 12 months of age were separated by two-dimensional electrophoresis. Approximately 900 discrete spots were resolved from both sets of samples. Representative gels from 6-month-old offspring are shown in Fig. 1a, b.

Analysis of the spot densities in the liver samples from animals at 6 months of age identified 41 differentially abundant proteins $(P<0.05), 18$ upregulated and 23 downregulated in MD compared to CON. These differentially abundant proteins were sequenced by mass spectrometry and are shown grouped by function, in Table 1. The proteins can be classified into three principal groups associated with energy metabolism, antioxidant defence, and amino acid and peptide metabolism. Additionally there were a small number of proteins with no clear functional relationships.

To validate the protein identification by mass spectrometry, duplicate samples were run on similar gels, blotted onto membranes and probed with antibodies specific to two of the differentially abundant proteins PGK-1 (Fig. 1c, d) and GAPDH (Fig. 1e, f). In both cases, these Western blots revealed a number of isoforms of similar molecular weight but differing in their isoelectric points.
The differentially abundant spots identified as PGK-1 and GAPDH on the coomassie stained gels both correspond closely to one of the minor isoforms, but because of slight distortions during processing, it was not possible to unambiguously align the differentially expressed proteins with particular spots on the Western blot.

In the samples derived from the livers of the 12-monthold animals, 15 differentially abundant proteins were identified, 7 upregulated and 8 downregulated in MD compared to $\mathrm{CON}(P<0.05)$. These proteins were sequenced by mass spectrometry and are shown grouped by function in Table 2. The proteins can be classified into three principal groups of proteins associated with energy metabolism, antioxidant defence and amino acid and peptide metabolism.

\section{Gene expression}

The relative expression of the mRNAs coding for three of the differentially abundant proteins, namely PEPCK, glyceraldehyde-3-phosphate dehydrogenase (GAPDH) and UDP-glucose dehydrogenase (Udpgdh) in the livers of 6 month male offspring is shown in Table 3. The mRNAs were unchanged despite changes in the protein levels. There were also no differences in the levels of the mRNAs for PPAR-alpha, PPAR-gamma, SREBP-1c or glucocorticoid receptor (GccR), all of which have been associated with the development of postnatal phenotypes in other animal models of programming. There were also no changes in the levels of mRNA coding for Acc-1 and L-CPT-1 also associated with other programming models.

\section{Enzyme activities}

The activity of PEPCK and GAPDH in homogenates prepared from the livers of the male offspring at 6 months of age is shown in Table 4. The activity of both enzymes was unchanged by the maternal diet.

\section{Discussion}

This study shows that the abundance of proteins in three different functional groups is changed in the offspring of dams exposed to a methyl-deficient diet during the preconception and preimplantation stages of development. At both 6 and 12 months of age, proteins involved in the processes of energy metabolism, antioxidant defence and amino acid and peptide metabolism are differentially expressed, suggesting that life-long changes in these processes are programmed by exposure to a nutritional insult during the initial cell divisions. The change in proteins associated with energy metabolism is consistent with the 
Fig. 1 Typical 2-D gels of soluble proteins from the liver of 6-month-old male offspring from dams fed complete (CON) or methyl-deficient (MD) diets. Panels (a) and (b) show gels stained with coomassie blue, with the arrows indicating the approximate location of the differentially abundant proteins identified as PGK1 and GAPDH. Panels (c) and (d) show corresponding Western blots with primary antibody specific to PGK1, and panels (e) and (f) show the Western blot with primary antibody specific to GAPDH.

The pI range is shown across the top, and the location of molecular weight markers (BioRad) are shown on the right-hand side

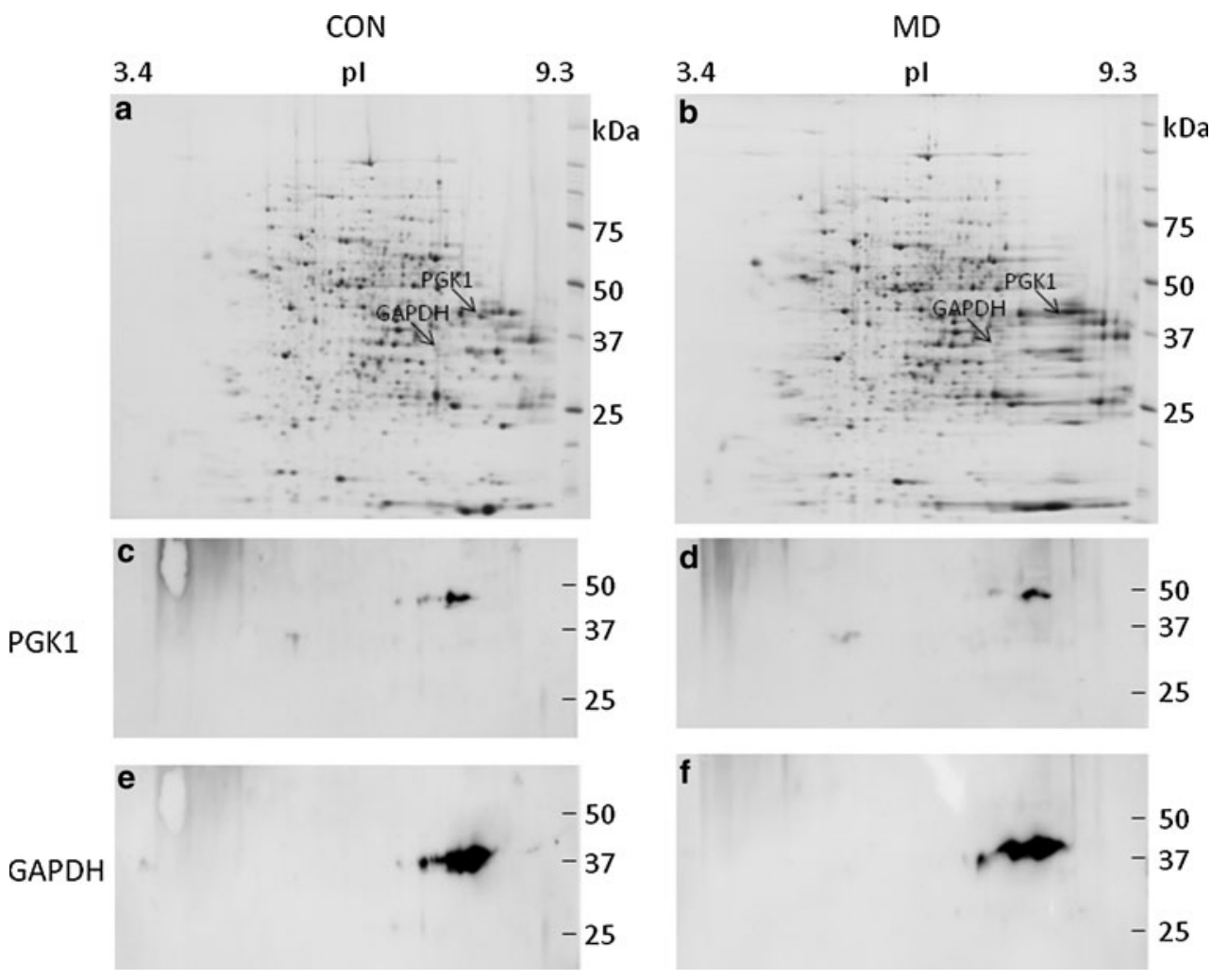

findings of physiological studies conducted whilst these animals were alive, which showed alterations in insulin action and glucose metabolism (Maloney et al. 2011).

Despite changes in the relative abundance of a protein identified as GAPDH in the livers of 6-month-old MD offspring, there was no change in either the mRNA levels or the total enzyme activity. The Western blots show that there are a number of GAPDH isoforms which differ only in their isoelectric points. These are probably caused by modifications, such as acetylation, methylation or phosphorylation, which alter the overall electric charge but have little effect on the apparent molecular weight. The minor GAPDH isoforms located in the region of the spot identified as GAPDH on the gels stained with coomassie blue accounted for between 3 and $5 \%$ of the total antibody binding. This suggests that the differentially abundant protein represents only a small part of the total activity within the cell, whereas the mRNA and enzyme activity reflects the sum of all isoforms of the enzyme. A similar situation probably applies to PGK1, another differentially abundant protein with multiple isoforms. Posttranslational modifications may well underlie the differential abundance of other proteins although this remains to be tested. Specific posttranscriptional modifications of proteins within particular pools or intracellular structures are a critical factor in metabolic channelling and regulation (Guan and Xiong 2011). Although GAPDH is mainly known for its role in glycolysis, there is a growing body of evidence to suggest that this is a multifunctional protein participating in the control of proliferation, apoptosis and transcription (Nicholls et al. 2011). Whilst these differentially abundant protein isoforms may be a relatively small part of the total activity, changes in them may result in much larger effects on metabolism within specific compartments or organelles and may be particularly important in the developmental origins of health and disease.

The mRNA for PEPCK, one of the differentially abundant proteins at 6 months of age, is increased in the foetal liver when animals are exposed to low-protein diet during preimplantation development (Kwong et al. 2007). This enzyme is also changed in the offspring of animals exposed to maternal diets low in protein (LP) or high in fat (HF) throughout gestation. This suggests that modifications of PEPCK may be a common feature of programming models, although there appear to be at least two mechanisms. In the case of the LP model, the changes in PEPCK activity are the result of programmed glucocorticoid signalling (Nyirenda et al. 2001). In the present study, we have been unable to detect a change in the expression of the glucocorticoid receptor (GccR) mRNA (Nyirenda et al. 1998), an observation that would tend to rule out a possible role for glucocorticoids in the early MD model. In the offspring of dams fed the HF diet, there is evidence for a second mechanism involving modifications in the histone code in the livers of the offspring which increase transcription of the PEPCK gene (Strakovsky et al. 2011). However, it is 
Table 1 Hepatic proteome of the male offspring at 6 months of age

\begin{tabular}{|c|c|c|c|c|c|c|c|}
\hline \multirow[t]{2}{*}{ Spot ID no } & \multirow[t]{2}{*}{ Protein identity } & \multirow[t]{2}{*}{ NCBI } & \multicolumn{2}{|l|}{$\mathrm{CON}$} & \multicolumn{2}{|l|}{ MD } & \multirow[t]{2}{*}{$P$} \\
\hline & & & Mean & SEM & Mean & SEM & \\
\hline \multicolumn{8}{|c|}{ Energy metabolism } \\
\hline 7301 & Glyceraldehyde-3-phosphate dehydrogenase (EC 1.2.1.12). & P04797 & 62.3 & 6.5 & 26.1 & 4.8 & 0.000 \\
\hline 6605 & UDP-glucose dehydrogenase & O70199 & 32.3 & 3.3 & 17.8 & 2.7 & 0.002 \\
\hline 7601 & UDP-glucose 6-dehydrogenase & O70199 & 8.4 & 2.0 & 3.1 & 1.0 & 0.015 \\
\hline 5714 & PEPCK cytosolic & P07379 & 23.2 & 8.9 & 3.9 & 1.1 & 0.026 \\
\hline 8401 & Phosphoglycerate kinase & P16617 & 262.3 & 16.1 & 163.5 & 46.3 & 0.035 \\
\hline 5702 & Phosphoglucomutase & Q499Q4 & 43.2 & 14.1 & 13.8 & 4.1 & 0.036 \\
\hline 8315 & Fructose-bisphosphate aldolase & P00884 & 684.0 & 107.9 & 383.1 & 113.2 & 0.043 \\
\hline 6507 & UDP-glucose pyrophosphorylase 2 & Q4V8I9 & 94.5 & 6.5 & 68.8 & 8.0 & 0.012 \\
\hline 4305 & Pyridoxal kinase & O35331 & 8.3 & 1.0 & 13.5 & 2.0 & 0.019 \\
\hline 8602 & Methyl-malonate semi-aldehyde dehydrogenase & Q02253 & 30.2 & 7.2 & 59.9 & 9.7 & 0.013 \\
\hline 7404 & Fumarate hydratase precursor, mitochondrial & Q5M964 & 73.7 & 10.5 & 47.4 & 5.5 & 0.023 \\
\hline 5408 & Fumarylacetoacetase & P25093 & 27.2 & 6.6 & 13.6 & 2.1 & 0.040 \\
\hline 6001 & Nucleoside diphosphate kinase & P19804 & 35.8 & 2.8 & 28.4 & 2.5 & 0.040 \\
\hline 2404 & 5'-bisphosphate nucleotidase & Q9Z1N4 & 9.2 & 1.8 & 15.2 & 2.6 & 0.044 \\
\hline 6708 & Glucokinase regulatory protein & Q07071 & 14.7 & 5.2 & 2.4 & 0.4 & 0.016 \\
\hline \multicolumn{8}{|c|}{ Antioxidant defence } \\
\hline 7702 & Catalase & P04762 & 67.1 & 8.4 & 128.2 & 19.8 & 0.005 \\
\hline 7602 & Catalase & P04762 & 418.1 & 59.1 & 270.3 & 19.1 & 0.016 \\
\hline 6703 & Catalase & P04762 & 115.0 & 9.4 & 91.8 & 6.6 & 0.035 \\
\hline 7103 & Glutathione transferase cytosolic & P04906 & 11.2 & 2.5 & 24.2 & 4.2 & 0.008 \\
\hline 7104 & Glutathione-S transferase & P08009 & 18.8 & 4.9 & 5.7 & 2.0 & 0.013 \\
\hline 7004 & Thioredoxin reductase (peroxiredoxin-4) & Q9Z0V5 & 55.1 & 5.3 & 33.9 & 7.5 & 0.019 \\
\hline 4504 & Selenium binding protein & Q8VIF7 & 149.7 & 8.7 & 200.2 & 25.3 & 0.047 \\
\hline 4106 & Peroxiredoxin-6 (EC 1.11.1.15) & $\mathrm{O} 35244$ & 19.0 & 2.7 & 27.9 & 2.8 & 0.019 \\
\hline \multicolumn{8}{|c|}{ Amino acid and peptide metabolism } \\
\hline 6602 & Cysteine sulphinic acid decarboxylase & Q64611 & 15.4 & 2.6 & 8.7 & 2.4 & 0.048 \\
\hline 2206 & 3-hydroxyanthranilate 3,4-dioxygenase & P46953 & 9.0 & 2.1 & 18.2 & 3.0 & 0.013 \\
\hline 7901 & Carbamoyl-phosphate synthetase & P07756 & 8.1 & 1.3 & 30.3 & 9.4 & 0.018 \\
\hline 5902 & Carbamoyl-phosphate synthetase & P07756 & 7.5 & 1.8 & 15.0 & 2.9 & 0.023 \\
\hline 908 & Carbamoyl-phosphate synthetase & P07756 & 8.0 & 3.9 & 0.5 & 0.3 & 0.044 \\
\hline 2608 & Dipeptidase 3 (rat) & Q5U2X4 & 6.4 & 0.7 & 8.6 & 0.4 & 0.006 \\
\hline 5302 & Arginase & P07824 & 69.5 & 9.0 & 41.6 & 9.6 & 0.028 \\
\hline 6504 & Homogentisate 1,2-dioxygenase & Q6AYR0 & 12.4 & 2.6 & 21.7 & 3.7 & 0.032 \\
\hline \multicolumn{8}{|c|}{ Miscellaneous } \\
\hline 1007 & BAB24222 (Mus musculus) & UNK & 4.8 & 0.7 & 7.8 & 1.2 & 0.020 \\
\hline 1203 & Annexin IV (36-kDa zymogen granule membrane) & Q5U362 & 15.1 & 2.2 & 20.2 & 1.3 & 0.038 \\
\hline 2706 & Choline dehydrogenase & Q6UPE0 & 5.6 & 0.5 & 8.6 & 1.1 & 0.016 \\
\hline 3005 & Bendless protein (Ubiquitin-conjugating enezyme E2) & Q9EQX9 & 4.2 & 0.4 & 5.9 & 0.8 & 0.047 \\
\hline 4810 & Formyltetrahydrofolate dehydrogenase (EC 1.5.1.6) & P28037 & 3.8 & 0.6 & 6.2 & 1.0 & 0.035 \\
\hline 5308 & 3-alpha-hydroxysteroid dehydrogenase & P23457 & 69.6 & 4.0 & 58.0 & 4.8 & 0.048 \\
\hline 6209 & Thyroid hormone sulphotransferase & P52847 & 39.8 & 4.9 & 27.1 & 2.5 & 0.018 \\
\hline 6802 & Serotransferrin, Liver regeneration related protein LLRG03 & P12346 & 51.6 & 7.1 & 34.8 & 4.2 & 0.034 \\
\hline 7302 & Dynamin-1-like protein & $\mathrm{O} 35303$ & 23.3 & 3.7 & 10.7 & 2.0 & 0.004 \\
\hline 8508 & Betaine-homocysteine S-methyltransferase 1 & O09171 & 47.7 & 21.5 & 132.8 & 37.2 & 0.038 \\
\hline
\end{tabular}

Offspring were from dams fed complete (CON) or methyl-deficient (MD) diets. Data are mean pixel density \pm SEM, $n=8$ in each group. Data compared by Student's $t$ test 
important to note that the tissues used in the present study were derived from animals that had been subjected to a glucose tolerance test $3 \mathrm{~h}$ earlier. As a result, the liver will have been insulin stimulated in vivo, and since insulin specifically inhibits transcription of the PEPCK gene (Granner et al. 1983), changes in the rate of transcription may be masked.
There is no evidence for changes in the abundance of proteins associated with lipid metabolism in the early MD offspring, unlike those of dams exposed to HF or LP diets. This is also apparent in the expression of mRNAs for both key enzymes and regulators. For example, HF diets fed throughout gestation upregulate the expression of PPARalpha and L-CPT-1 in the liver (Zhang et al. 2009). The

Table 2 Hepatic proteome of the male offspring at 12 months of age

\begin{tabular}{|c|c|c|c|c|c|c|c|}
\hline \multirow[t]{2}{*}{ Spot ID no } & \multirow[t]{2}{*}{ ID } & \multirow[t]{2}{*}{ NCBI } & \multicolumn{2}{|l|}{$\mathrm{CON}$} & \multicolumn{2}{|l|}{ MD } & \multirow[t]{2}{*}{$P$} \\
\hline & & & Mean & SEM & Mean & SEM & \\
\hline \multicolumn{8}{|c|}{ Energy metabolism } \\
\hline 8302 & L-lactate dehydrogenase (EC 1.1.1.27) chain M & P04642 & 426.3 & 52.5 & 264.4 & 28.7 & 0.022 \\
\hline 2009 & Cytidylate kinase & Q4KM73 & 58.2 & 5.0 & 43.9 & 3.5 & 0.049 \\
\hline 6606 & UDP-glucose pyrophosphorylase 2 . & Q4V8I9 & 158.6 & 18.9 & 104.2 & 13.8 & 0.045 \\
\hline 4207 & Electron transfer flavoprotein subunit beta (beta-ETF) & Q68FU3 & 145.2 & 5.7 & 178.8 & 13.5 & 0.026 \\
\hline \multicolumn{8}{|c|}{ Antioxidant defence } \\
\hline 7604 & Catalase (EC 1.11.1.6). & P04762 & 142.6 & 9.4 & 85.4 & 17.9 & 0.009 \\
\hline 4213 & HAGH (Hydroxyacylglutathione hydrolase) protein & O35952 & 10.8 & 2.6 & 20.9 & 3.1 & 0.023 \\
\hline 3606 & Selenium binding protein 2 . & Q8VIF7 & 235.9 & 23.1 & 341.8 & 41.6 & 0.031 \\
\hline 3801 & 5-oxoprolinase (ATP-hydrolysing) (EC 3.5.2.9) & P97608 & 9.4 & 1.6 & 5.2 & 0.8 & 0.046 \\
\hline \multicolumn{8}{|c|}{ Amino acid and peptide metabolism } \\
\hline 5307 & Ornithine carbamoyltransferase (EC 2.1.3.3) precursor & P00481 & 102.2 & 8.5 & 69.5 & 3.5 & 0.006 \\
\hline 2811 & Acylaminoacyl peptidase (EC 3.4.19.1) & P13676 & 8.8 & 1.9 & 16.9 & 3.0 & 0.033 \\
\hline 6402 & Aspartate transaminase (EC 2.6.1.1), cytosolic & P13221 & 288.6 & 26.7 & 209.5 & 18.5 & 0.038 \\
\hline \multicolumn{8}{|c|}{ Miscellaneous } \\
\hline 2515 & Aldehyde dehydrogenase 9 family, member A1 & Q9JLJ3 & 318.0 & 29.6 & 502.1 & 63.7 & 0.012 \\
\hline 3808 & Mannosidase, alpha, class 2C, member 1 . & Q5M9I2 & 4.3 & 0.7 & 7.6 & 1.0 & 0.015 \\
\hline 5305 & 3-oxo-5-beta-steroid 4-dehydrogenase (EC 1.3.99.6) & P31210 & 56.4 & 10.3 & 125.6 & 27.1 & 0.020 \\
\hline 4303 & 3-oxo-5-beta-steroid 4-dehydrogenase (EC 1.3.99.6) & P31210 & 408.9 & 54.8 & 604.9 & 54.5 & 0.026 \\
\hline
\end{tabular}

Offspring were from dams fed complete (CON) or methyl-deficient (MD) diets. Data are mean pixel density \pm SEM, $n=9$ for CON and $n=7$ for MD. Data compared by Student's $t$ test

Table 3 Gene expression in the liver of male offspring at 6 months of age

\begin{tabular}{|c|c|c|c|c|c|c|}
\hline \multirow[t]{2}{*}{ Gene } & \multirow[t]{2}{*}{$n$} & \multicolumn{2}{|l|}{$\mathrm{CON}$} & \multicolumn{2}{|l|}{$\mathrm{MD}$} & \multirow[t]{2}{*}{$P$} \\
\hline & & Mean & SEM & Mean & SEM & \\
\hline $\operatorname{PEPCK}(\mathrm{T})$ & 16 & 3.39 & 0.31 & 4.07 & 0.35 & 0.157 \\
\hline GAPDH(T) & 16 & 2.80 & 0.10 & 3.03 & 0.13 & 0.162 \\
\hline UGDH(T) & 8 & 5.69 & 0.14 & 6.03 & 0.28 & 0.298 \\
\hline PPAR-alpha & 8 & 5.39 & 0.26 & 5.90 & 0.45 & 0.340 \\
\hline PPAR-gamma & 16 & 6.06 & 0.61 & 6.36 & 0.47 & 0.704 \\
\hline SREBP-1c & 16 & 1.48 & 0.13 & 1.61 & 0.12 & 0.461 \\
\hline GccR & 16 & 3.69 & 0.13 & 3.76 & 0.17 & 0.719 \\
\hline ACC-1 & 8 & 5.88 & 0.40 & 6.06 & 0.07 & 0.817 \\
\hline L-CPT & 16 & 2.53 & 0.15 & 2.68 & 0.17 & 0.521 \\
\hline
\end{tabular}

Offspring were from dams fed complete (CON) or methyl-deficient (MD) diets. All data are expressed in arbitrary units as relative expression corrected for 18S rRNA. $n=$ number of animals, 1 per litter chosen at random from the total pool of 18 litters (CON) and 17 litters (MD). Data compared by Student's $t$ test 
Table 4 Enzyme activities in liver homogenates prepared from male offspring at 6 months of age

\begin{tabular}{|c|c|c|c|c|c|}
\hline \multirow[t]{2}{*}{ Enzyme activity $\mathrm{nmol} / \mathrm{min} / \mathrm{mg}$ protein } & \multicolumn{2}{|l|}{$\mathrm{CON}$} & \multicolumn{2}{|l|}{ MD } & \multirow[t]{2}{*}{$P$} \\
\hline & Mean & SEM & Mean & SEM & \\
\hline PEPCK & 0.34 & 0.08 & 0.39 & 0.06 & 0.649 \\
\hline GAPDH & 199.7 & 10.5 & 181.7 & 7.6 & 0.183 \\
\hline
\end{tabular}

Offspring were from dams fed complete (CON) or methyl-deficient (MD) diets. The homogenate was prepared from a sample of the same liver used for the proteome analysis. Data compared by Student's $t$ test, $n=8$

expression of both ACC-1 and L-CPT-1 is also increased in LP offspring (Maloney et al. 2003, 2007) possibly mediated by an increase in PPAR-alpha expression (Lillycrop et al. 2005). In the LP model, there are also increases in SREBP-1c expression mediated by glucocorticoid signalling (Erhuma et al. 2009). However, in the early MD model, there is no evidence for changes in expression of ACC-1 and L-CPT-1 mRNAs or in the mRNAs for PPARalpha, SREBP-1c or glucocorticoid receptor. This important difference suggests that the events programming hepatic fat metabolism through PPAR isoforms or SREBP1c occur later in foetal development.

In addition to proteins involved in carbohydrate metabolism and the management of glycogen reserves, the list of differentially expressed proteins associated with energy metabolism also includes proteins with functions in oxidative metabolism. These include proteins that transfer substrates to the mitochondria, suggesting that the change in metabolism extends beyond carbohydrates to include oxidative metabolism by the mitochondrion. Further evidence for a change in oxidative metabolism comes from the differential abundance of a group of proteins associated with antioxidant defence. These proteins are produced in response to free radicals, an unwanted and harmful byproduct of metabolic activity, and correlate with changes in mitochondrial activity (Aiken et al. 2008). The products of oxidative damage include proteins and lipids, and the processes that remove them are represented in the group of proteins associated with amino acid and peptide metabolism. Denatured proteins are rapidly degraded by the proteosome (Breusing and Grune 2008), and the resulting peptides are hydrolysed to amino acids by acylaminoacyl peptidase (Shimizu et al. 2004). Peroxiredoxin-6 (Prdx6) also has an important role in antioxidant defence through the metabolism of peroxidised membrane phospholipids (Roede et al. 2009). These results suggest that the differential abundance of proteins associated with antioxidant defence, amino acid and peptide metabolism is probably linked by changes in oxidative metabolism and the production of free radicals. Changes in antioxidant defence are a common feature in the proteome of many animal models of both insulin resistance (Schmid et al. 2004) and metabolic programming (Lillycrop et al. 2010; Mortensen et al. 2010a, b). In these models, alterations in mitochondrial function underlie the change in metabolic activity. There is also direct evidence for programming of mitochondrial function by methyl deficiency during development. The offspring of dams subjected to methyl-deficient diets during gestation and lactation also exhibit changes in oxidative metabolism of the myocardium, mediated through imbalanced methylation/acetylation of PGC- $1 \alpha$ (Garcia et al. 2011). These changes in both the methylation and acetylation of the PGC- $1 \alpha$ protein are strikingly similar to the present findings where low molecular weight modifications influence the abundance of both PGK1 and GAPDH isoforms. These cumulative data suggest that the mitochondria may be a major target in the early MD model of metabolic programming.

The mitochondria of the developing foetus are derived exclusively from the oocyte. Having established the full complement of mitochondria in the fully grown oocyte, there is no further increase in the mitochondrial population during early development (Dumollard et al. 2007). Changes in maternal metabolism such as those produced by maternal diabetes have been shown to modify mitochondrial function in the oocyte (Wang and Moley 2010). Maternal diet also modifies mitochondrial potential. In the case of mice fed high-fat diets, there was a fall in mitochondrial DNA content and biogenesis in the preimplantation embryo, and the obese dams were less able to support blastocyst formation (Igosheva et al. 2010). A reduction in the litter size was also a feature of the early MD dams (CON 12.9 vs. MD 10.7 pups per litter) (Maloney et al. 2011), and it is possible that the extensive changes in lipid metabolism in the maternal liver of dams fed the MD diet (McNeil et al. 2008) may be affecting oocyte quality and mitochondria in the same way as the high-fat diets. The MD diet may be selecting those embryos with a higher mitochondrial density leading to long-term changes in metabolism with the posttranslational modification of proteins acting as a possible regulatory mechanism.

Acknowledgments This study is supported by NIH (U01 HD044638 to KDS) as a component of the NICHD Cooperative Program on Female Health and Egg Quality and by the Scottish Government Rural and Environmental Research and Analysis 
Directorate (RERAD) as part of the core funding of the Rowett Institute of Nutrition and Health (WDR).We wish to express our thanks to staff from Bioresources Unit for animal care.

\section{References}

Aiken CE, Cindrova-Davies T, Johnson MH (2008) Variations in mouse mitochondrial DNA copy number from fertilization to birth are associated with oxidative stress. Reprod Biomed Online $17: 806-813$

Bogdarina I, Welham S, King PJ, Burns SP, Clark AJL (2007) Epigenetic modification of the renin-angiotensin system in the fetal programming of hypertension. Circ Res 100:520-526

Bogdarina I, Haase A, Langley-Evans S, Clark AJL (2010) Glucocorticoid effects on the programming of AT1b angiotensin receptor gene methylation and expression in the rat. PLoS ONE 5:e9237

Breusing N, Grune T (2008) Regulation of proteasome-mediated protein degradation during oxidative stress and aging. Biol Chem 389:203-209

Desai M, Byrne CD, Meeran K, Martenz ND, Bloom SR, Hales CN (1997) Regulation of hepatic enzymes and insulin levels in offspring of rat dams fed a reduced-protein diet. Am J Physiol 273:G899-G904

Dumollard R, Duchen M, Carroll J (2007) The role of mitochondrial function in the oocyte and embryo. In: Justin CS (ed) Current topics in developmental biology, The mitochondrion in the germline and early development. Academic Press, USA, pp 21-49

Erhuma A, McMullen S, Langley-Evans S, Bennett A (2009) Feeding pregnant rats a low-protein diet alters the hepatic expression of SREBP-1c in their offspring via a glucocorticoid-related mechanism. Endocrine 36:333-338

Fernandez-Gonzalez R, Moreira P, Bilbao A, Jiminez A, PerezCrespo M, Ramirez MA, De Fonseca FR, Pintado B, GutierrezAdan A (2004) Long-term effect of in vitro culture of mouse embryos with serum on mRNA expression of imprinting genes, development, and behavior. Proc Nat Acad Sci USA 101:58805885

Garcia MM, Gueant-Rodriguez RM, Pooya S et al (2011) Methyl donor deficiency induces cardiomyopathy through altered methylation/acetylation of PGC-1alpha by PRMT1 and SIRT1. J Pathol 255:324-335

Granner D, Andreone T, Sasaki K, Beale E (1983) Inhibition of transcription of the phosphoenolpyruvate carboxykinase gene by insulin. Nature 305:549-551

Guan KL, Xiong Y (2011) Regulation of intermediary metabolism by protein acetylation. Trends Biochem Sci 36:108-116

Hochberg Z, Feil R, Constancia M et al (2010) Child health, developmental plasticity, and epigenetic programming. Endocr Rev 32:159-224

Igosheva N, Abramov AY, Poston L, Eckert JJ, Fleming TP, Duchen MR, McConnell J (2010) Maternal diet-induced obesity alters mitochondrial activity and redox status in mouse oocytes and zygotes. PLoS ONE 5:e10074

Kwong WY, Miller DJ, Wilkins AP, Dear MS, Wright JN, Osmond C, Zhang J, Fleming TP (2007) Maternal low protein diet restricted to the preimplantation period induces a gender-specific change on hepatic gene expression in rat fetuses. Mol Reprod Dev 74:48-56

Lillycrop KA, Phillips ES, Jackson AA, Hanson MA, Burdge GC (2005) Dietary protein restriction of pregnant rats induces and folic acid supplementation prevents epigenetic modification of hepatic gene expression in the offspring. J Nutr 135:1382-1386
Lillycrop KA, Rodford J, Garratt ES, Slater-Jefferies JL, Godfrey KM, Gluckman PD, Hanson MA, Burdge GC (2010) Maternal protein restriction with or without folic acid supplementation during pregnancy alters the hepatic transcriptome in adult male rats. Br J Nutr 103:1711-1719

Maloney CA, Gosby AK, Phuyal JL, Denyer GS, Bryson JM, Caterson ID (2003) Site-specific changes in the expression of fatpartitioning genes in weanling rats exposed to a low-protein diet in utero. Obesity Res 11:461-468

Maloney CA, Lilley C, Cruickshank M, McKinnon C, Hay SM, Rees WD (2005) The expression of growth-arrest genes in the liver and kidney of the protein-restricted rat fetus. Br J Nutr 94:12-18

Maloney CA, Lilley C, Czopek A, Hay SM, Rees WD (2007) Interactions between protein and vegetable oils in the maternal diet determine the programming of the insulin axis in the rat. $\mathrm{Br}$ J Nutr 97:912-920

Maloney CA, Hay SM, Young LE, Sinclair KD, Rees WD (2011) A methyl-deficient diet fed to rat dams during the peri-conception period programs glucose homeostasis in adult male but not female offspring. J Nutr 141:95-100

McNeil CJ, Hay SM, Rucklidge G, Reid M, Duncan G, Maloney CA, Rees WD (2008) Disruption of lipid metabolism in the liver of the pregnant rat fed folate deficient and methyl donor deficient diets. Br J Nutr 99:262-271

Mortensen OH, Olsen HL, Frandsen L, Nielsen PE, Nielsen FC, Grunnet N, Quistorff B (2010a) A maternal low protein diet has pronounced effects on mitochondrial gene expression in offspring liver and skeletal muscle; protective effect of taurine. J Biomed Sci 17(Suppl 1):S38

Mortensen OH, Olsen HL, Frandsen L, Nielsen PE, Nielsen FC, Grunnet N, Quistorff B (2010b) Gestational protein restriction in mice has pronounced effects on gene expression in newborn offspring's liver and skeletal muscle; protective effect of taurine. Pediatr Res 67:47-53

Nicholls C, Li H, Liu JP (2011) GAPDH: a common enzyme with uncommon functions. Clin Exp Pharmacol Physiol 39:674-679

Nyirenda MJ, Lindsay RS, Kenyon CJ, Burchell A, Seckl JR (1998) Glucocorticoid exposure in late gestation permanently programs rat hepatic phosphoenolpyruvate carboxykinase and glucocorticoid receptor expression and causes glucose intolerance in adult offspring. J Clin Invest 101:2174-2181

Nyirenda MJ, Welberg LA, Seckl JR (2001) Programming hyperglycaemia in the rat through prenatal exposure to glucocorticoids-fetal effect or maternal influence? J Endocrinol 170:653660

Petrescu I, Bojan O, Saied M, Barzu O, Schmidt F, Kuhnle HF (1979) Determination of phosphoenolpyruvate carboxykinase activity with deoxyguanosine $5^{\prime}$-diphosphate as nucleotide substrate. Anal Biochem 96:279-281

Rees WD, Hay SM, Cruickshank M, Reusens B, Remacle C, Antipatis C, Grant G (2006) Maternal protein intake in the pregnant rat programs the insulin axis and body composition in the offspring. Metabolism 55:642-649

Roede JR, Orlicky DJ, Fisher AB, Petersen DR (2009) Overexpression of peroxiredoxin 6 does not prevent ethanol-mediated oxidative stress and may play a role in hepatic lipid accumulation. J Pharmacol Exp Ther 330:79-88

Sandovici I, Smith NH, Nitert MD et al (2011) Maternal diet and aging alter the epigenetic control of a promoter-enhancer interaction at the Hnf4a gene in rat pancreatic islets. Proc Natl Acad Sci USA 108:5449-5454

Santos F, Dean W (2004) Epigenetic reprogramming during early development in mammals. Reproduction 127:643-651

Schmid GM, Converset V, Walter N, Sennitt MV, Leung KY, Byers $\mathrm{H}$, Ward M, Hochstrasser DF, Cawthorne MA, Sanchez JC (2004) Effect of high-fat diet on the expression of proteins in 
muscle, adipose tissues, and liver of C57BL/6 mice. Proteomics 4:2270-2282

Scott KA, Yamazaki Y, Yamamoto M, Lin Y, Melhorn SJ, Krause EG, Woods SC, Yanagimachi R, Sakai RR, Tamashiro KLK (2010) Glucose parameters are altered in mouse offspring produced by assisted reproductive technologies and somatic cell nuclear transfer. Biol Reprod 83:220-227

Shimizu K, Kiuchi Y, Ando K, Hayakawa M, Kikugawa K (2004) Coordination of oxidized protein hydrolase and the proteasome in the clearance of cytotoxic denatured proteins. Biochem Biophys Res Commun 324:140-146

Sinclair KD, Allegrucci C, Singh R et al (2007a) DNA methylation, insulin resistance, and blood pressure in offspring determined by maternal periconceptional B vitamin and methionine status. Proc Natl Acad Sci USA 104:19351-19356

Sinclair KD, Lea RG, Rees WD, Young LE (2007b) The developmental origins of health and disease: current theories and epigenetic mechanisms. Soc Reprod Fertil Suppl 64:425-443

Strakovsky RS, Zhang X, Zhou D, Pan YX (2011) Gestational high fat diet programs hepatic phosphoenolpyruvate carboxykinase gene expression and histone modification in neonatal offspring rats. J Physiol 589:2707-2717

Tamashiro KL, Wakayama T, Yamazaki Y, Akutsu H, Woods SC, Kondo S, Yanagimachi R, Sakai RR (2003) Phenotype of cloned mice: development, behavior, and physiology. Exp Biol Med (Maywood) 228:1193-1200 van Straten EME, Bloks VW, Huijkman NCA, Baller JFW, Meer HV, Lutjohann D, Kuipers F, Plosch T (2010) The liver X-receptor gene promoter is hypermethylated in a mouse model of prenatal protein restriction. Am J Physiol Regul Integr Comp Physiol 298:R275-R282

Wang Q, Moley KH (2010) Maternal diabetes and oocyte quality. Mitochondrion 10:403-410

Waterland RA, Jirtle RL (2003) Transposable elements: targets for early nutritional effects on epigenetic gene regulation. Mol Cell Biol 23:5293-5300

Waterland RA, Michels KB (2007) Epigenetic epidemiology of the developmental origins hypothesis. Annu Rev Nutr 27:363-388

Watts LM, Manchem VP, Leedom TA et al (2005) Reduction of hepatic and adipose tissue glucocorticoid receptor expression with antisense oligonucleotides improves hyperglycemia and hyperlipidemia in diabetic rodents without causing systemic glucocorticoid antagonism. Diabetes 54:1846-1853

Zhang J, Byrne CD (2000) Differential hepatic lobar gene expression in offspring exposed to altered maternal dietary protein intake. Am J Physiol Gastrointest Liver Physiol 278:G128-G136

Zhang J, Zhang F, Didelot X, Bruce K, Cagampang F, Vatish M, Hanson M, Lehnert H, Ceriello A, Byrne C (2009) Maternal high fat diet during pregnancy and lactation alters hepatic expression of insulin like growth factor-2 and key microRNAs in the adult offspring. BMC Genomics 10:478 